\title{
Selective ring-opening metathesis polymerization (ROMP) of cyclobutenes. Unsymmetrical ladderphane containing polycyclobutene and polynorbornene strands
}

\author{
Yuan-Zhen Ke ${ }^{1,2}$, Shou-Ling Huang ${ }^{1}$, Guoqiao Lai ${ }^{3}$ and Tien-Yau Luh*1
}

Open Access

\author{
Full Research Paper \\ Address: \\ ${ }^{1}$ Department of Chemistry, National Taiwan University, Taipei 106, \\ Taiwan, ${ }^{2}$ Shanghai Institute of Organic Chemistry, Chinese Academy \\ of Sciences, 345 Lingling Lu, Shanghai 200032, China and ${ }^{3}$ Key \\ Laboratory of Organosilicon Chemistry and Material Technology of \\ Ministry of Education, Hangzhou Normal University, Hangzhou, \\ Zhejiang 311121, China \\ Email: \\ Tien-Yau Luh ${ }^{*}$ - tyluh@ntu.edu.tw \\ ${ }^{*}$ Corresponding author

\section{Keywords:} \\ cyclobutene; hydrolysis; linker; metathesis; norbornene; ROMP; \\ selectivity; unsymmetrical ladderphane
}

Beilstein J. Org. Chem. 2019, 15, 44-51.

doi:10.3762/bjoc. 15.4

Received: 20 August 2018

Accepted: 04 December 2018

Published: 03 January 2019

This article is part of the thematic issue "Progress in metathesis chemistry III". In memory of the late Professor Teruaki Mukaiyama.

Guest Editors: K. Grela and A. Kajetanowicz

(C) 2019 Ke et al.; licensee Beilstein-Institut.

License and terms: see end of document.

\begin{abstract}
At $0{ }^{\circ} \mathrm{C}$ in THF in the presence of Grubbs first generation catalyst, cyclobutene derivatives undergo ROMP readily, whereas norbornene derivatives remain intact. When the substrate contains both cyclobutene and norbornene moieties, the conditions using THF as the solvent at $0{ }^{\circ} \mathrm{C}$ offer a useful protocol for the selective ROMP of cyclobutene to give norbornene-appended polycyclobutene. Unsymmetrical ladderphane having polycyclobutene and polynorbornene as two strands is obtained by further ROMP of the norbornene appended polycyclobutene in the presence of Grubbs first generation catalyst in DCM at ambient temperature. Methanolysis of this unsymmetrical ladderphane gives polycyclobutene methyl ester and insoluble polynorbornene-amide-alcohol. The latter is converted into the corresponding soluble acetate. Both polymers are well characterized by spectroscopic means. No norbornene moiety is found to be incorporated into polycyclobutene strand at all. The double bonds in the polycyclobutene strand are mainly in cis configuration (ca $70 \%$ ), whereas the $E / Z$ ratio for polynorbornene strand is 8:1.
\end{abstract}

\section{Introduction}

Ring-opening metathesis polymerizations (ROMP) of strained cycloalkenes offer a powerful arsenal for the synthesis of polymers having a variety of fascinating properties [1-3]. To illustrate this, polynorbornenes and polycyclobutenes are readily ob- tained from the corresponding monomeric norbornene and cyclobutene derivatives under various conditions. Symmetrical DNA-like double stranded ladderphanes are conveniently synthesized from bisnorbornene [4-15] or from biscyclobutene [16] 
linked with a range of different rigid linkers. When a flexible linker is used, bisnorbornene derivatives undergo cascade metathetical cyclopolymerization giving the corresponding polynorbornenes with hammock-like pendants $[17,18]$. Unsymmetrical polynorbornene-based ladderphane is obtained by a replication protocol from a single stranded polynorbornene [19,20]. Alternatively, sequential polymerization of a monomer containing a norbornene moiety and other polymerizable group furnishes an unsymmetrical ladderphane having two structurally different polymeric backbones [21,22]. It seems to be not easy if both strands are arisen from different strained rings by ROMP. It is known that norbornenes having different substituents would have different reaction rates in ROMP [23]. These discrepancies in reactivity have been used for sequence control in polymer synthesis [24]. Since the first living ROMP methods for cyclobutenes were reported in 1992 [25], cyclobutene-containing block copolymers are well documented [26-34]. Alternating cyclobutene-cyclohexene copolymers have been synthesized by ROMP of the corresponding monomers [31-33]. However, to the best of our knowledge, selective ROMPs between cyclobutene and norbornene have not been reported.

The strain energies for norbornene and cyclobutene are 25 and $31 \mathrm{kcal} / \mathrm{mol}$, respectively [35]. It is therefore envisaged that cyclobutene would react faster than norbornene under certain ROMP conditions. As such, when monomer 1 containing a cyclobutene moiety and a norbornene moiety connected by a bridge are subjected to ROMP, it would be feasible that the cyclobutene moiety would react preferentially giving the corresponding norbornene-appended polycyclobutene 2 . After all cyclobutene moieties have been consumed and quenched, further ROMP of 2 under different conditions would afford unsymmetrical double-stranded ladderphane 3 having both polycyclobutene and polynorbornene as two polymeric frameworks (Scheme 1). We have tested this viewpoint and now wish to report sequential ROMP of monomers containing both cyclobutene and norbornene moieties tethered by a linker.

\section{Results and Discussion}

\section{A comparison of the reactivity of cyclobutene versus norbornene derivatives 4 and 5 in ROMP catalyzed by Grubbs I catalyst (6)}

In the beginning of this study, we have examined the first order reaction kinetics of ROMPs of $\mathbf{4}$ and of $\mathbf{5}$ in the presence of $10 \mathrm{~mol}$ per cent of Grubbs first generation catalyst (6) [36] in $\mathrm{DCM}$ at $10{ }^{\circ} \mathrm{C}$ [37]. The rate constants for the reactions of 4 and 5 were $1.3 \times 10^{-3}$ and $5.1 \times 10^{-4} \mathrm{~s}^{-1}$, respectively. On the other hand, when the reaction was carried out in THF- $d_{8}$ at $273 \mathrm{~K}$, the second order rate constant for 4 was $2.1 \times 10^{-3} \mathrm{M}^{-1} \mathrm{~s}^{-1}$, whereas norbornene derivative $\mathbf{5}$ was inert

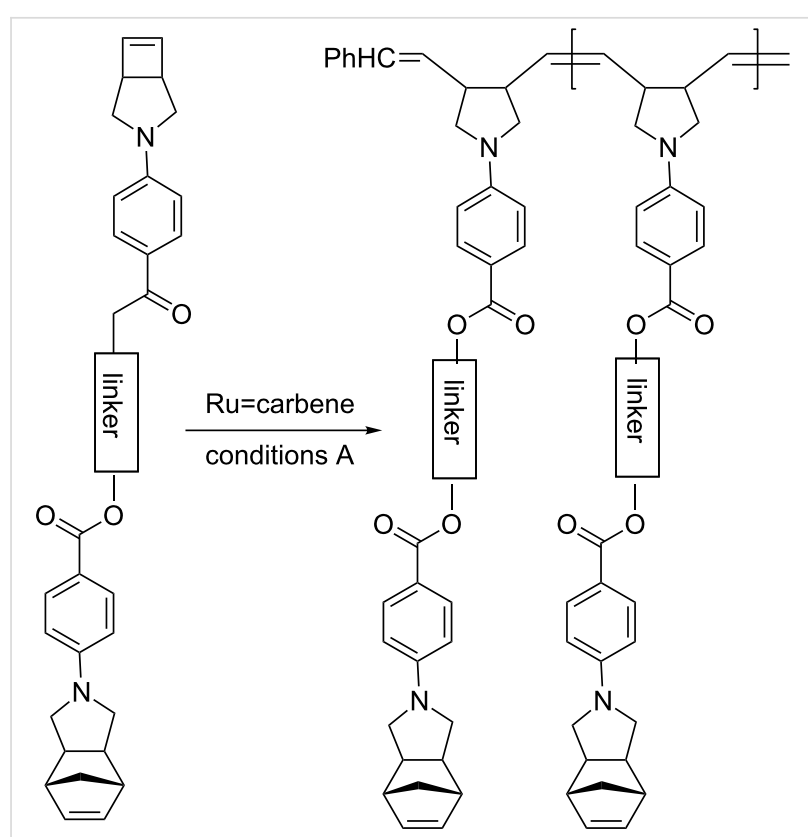

2

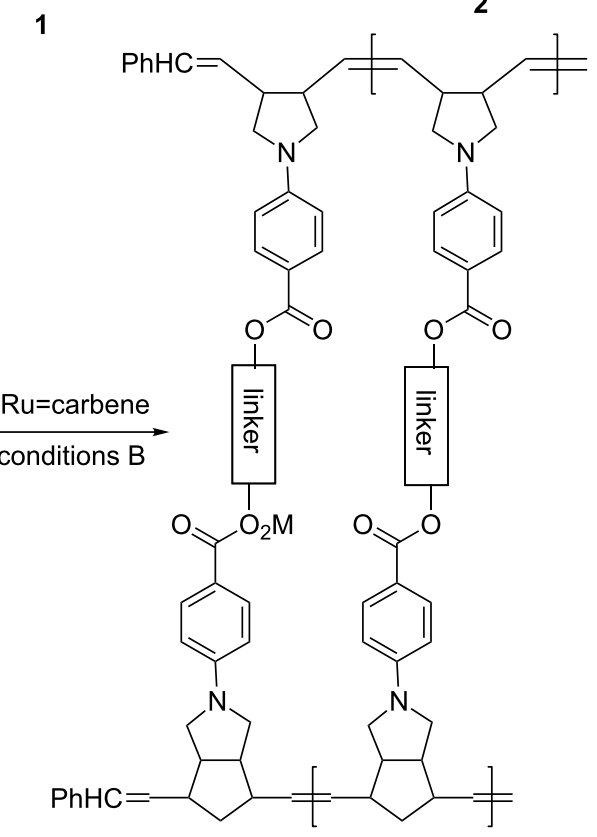

3

Scheme 1: Strategy for sequential ROMP of 1 to yield 3.

under these conditions. The details are described in the Experimental section and Supporting Information File 1 (Figures S1, S2 and S8-S10).

It has been suggested that the metathesis reaction may involve a fourteen-electron ruthenium species as the active catalyst [38-40]. This active species might be stabilized when the reaction is carried out in polar solvent having weak coordination ability such as THF [41-43]. As mentioned above, the difference in reactivity between the ROMP of $\mathbf{4}$ and $\mathbf{5}$ in THF at $0{ }^{\circ} \mathrm{C}$ 
would offer useful conditions to selectively react with $\mathbf{4}$ in the presence of $\mathbf{5}$. Thus, a mixture of an equal molar of $\mathbf{4}$ and $\mathbf{5}$ was treated with $10 \mathrm{~mol} \%$ of 6 in THF- $d_{8}$ at $0{ }^{\circ} \mathrm{C}$. Only 4 was consumed to give the corresponding polymer $\mathbf{7}$, whereas $\mathbf{5}$ remained intact (Scheme 2). This promising observation prompted us to pursue the synthesis of unsymmetrical doublestranded ladderphane 8 by sequential ROMPs of 9 (Scheme 3).

\section{Synthesis of monomer 9}

4-Aminobutanol (11) was used to link norbornene and cyclobutene moieties via amide and ester groups. The use of such a linker is because the ester group could be selectively hydrolyzed in the presence of amides. This selectivity will be helpful for the structural elucidation of polymer $\mathbf{8}$. Thus, $\mathbf{1 0 b}$ was allowed to react with $\mathbf{1 1}$ to afford amide-alcohol $\mathbf{1 2}$ in $79 \%$ yield. Esterification of $\mathbf{1 2}$ with $\mathbf{1 3 b}$ furnished $70 \%$ yield of monomer 9 (Scheme 4).

\section{Synthesis of unsymmetrical ladderphane 8 by sequential ROMPs catalyzed by 6}

Polymerization of monomer 9 in the presence of $10 \mathrm{~mol} \%$ of 6 was performed in THF at $0{ }^{\circ} \mathrm{C}$ for $4 \mathrm{~h}$, followed by quenching with ethyl vinyl ether to give polymer 14 in $86 \%$ yield (Scheme 5). It is worth noting that no incorporation of the norbornene moiety into the polymeric backbone under these conditions was observed. The ${ }^{1} \mathrm{H}$ NMR spectrum of $\mathbf{1 4}$ shows the olefinic proton signals at $\delta 5.49$ and $6.12 \mathrm{ppm}$ in $1: 1$ ratio. These signals were assigned to the absorptions of olefinic protons on the polymeric backbone and the olefinic proton of unreacted norbornene pendants, respectively. In the ${ }^{13} \mathrm{C}$ NMR spectrum, the peak at $\delta 139 \mathrm{ppm}$ owing to the olefinic carbon of

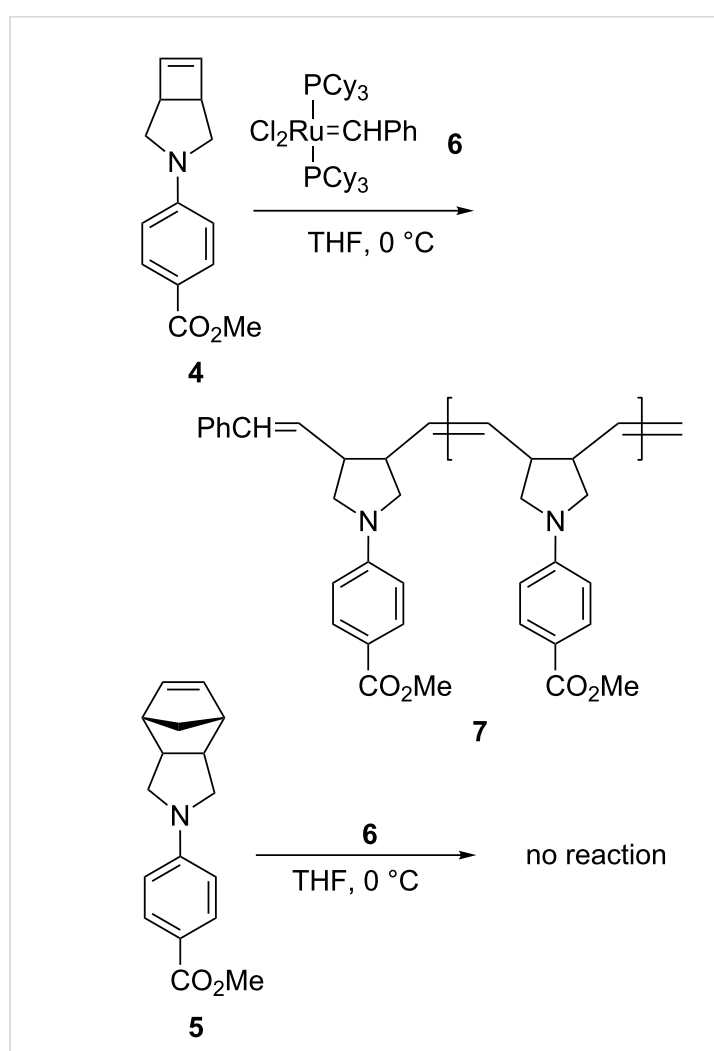

Scheme 2: ROMP of $\mathbf{4}$ and $\mathbf{5}$ in THF at $0{ }^{\circ} \mathrm{C}$ in the presence of $10 \mathrm{~mol} \%$ of 6 .

cyclobutene shifts to $\delta 130 \mathrm{ppm}$ due to ring opening, whereas the olefin carbon of the unreacted norbornene moiety at $\delta 136 \mathrm{ppm}$ remained unchanged after first polymerization. These observations are consistent with the results of our prelim-

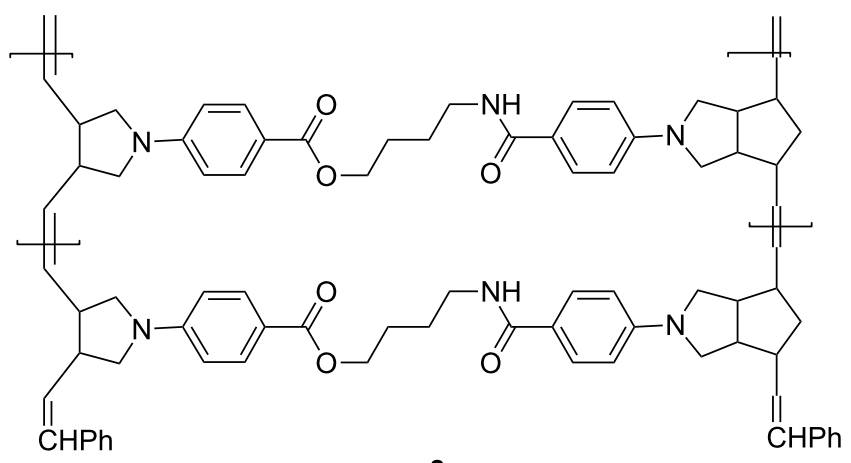

8

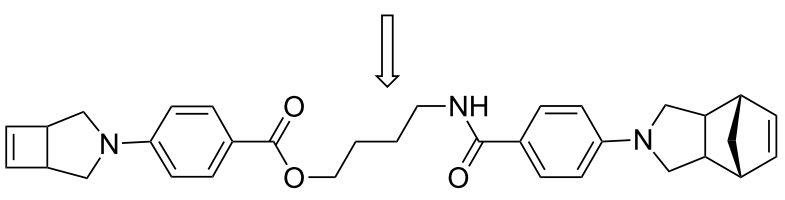




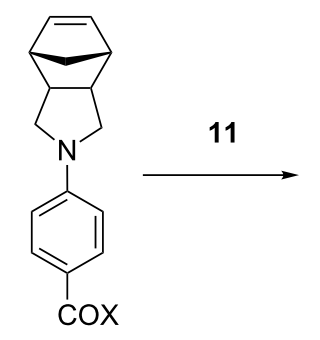

$10 \mathrm{a} X=\mathrm{OH}$

$10 \mathrm{~b} X=\mathrm{Cl}$

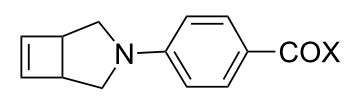

$13 \mathrm{a} X=\mathrm{OH}$

$13 b X=\mathrm{Cl}$

Scheme 4: Synthesis of monomer 9

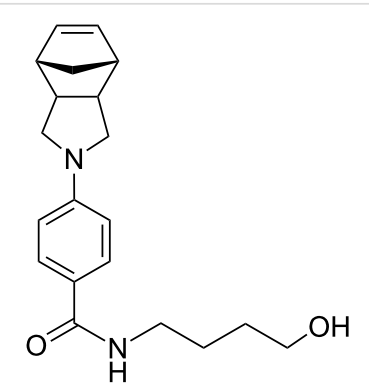

12

inary studies that only the cyclobutene moiety, but not norbornene in 9, proceeds 6-catalyzed ROMP under these conditions. The degree of polymerization of $\mathbf{1 4}$ was estimated to be 10 based on the ${ }^{1} \mathrm{H}$ NMR integration of relevant peaks.

We have previously found that two norbornene derivatives connected by a flexible linker 15 may undergo cascade ringopening-ring-closing metathesis polymerization to give singlestranded hammock-like appended polynorbornenes 17 (Scheme 6) $[17,18]$. The linker in $\mathbf{8}$ is flexible, and, therefore, the possibility for similar intramolecular metathesis cyclopolymerization might take place to form intermediate $\mathbf{1 6}$ for further transformations. However, no such reaction was observed in this study. Presumably, the 6-catalyzed metathesis reactivity of cyclobutenes would be much higher than that of norbornene derivatives. Accordingly, intermolecular metathesis reaction between two cyclobutene moieties would be favored over intramolecular ring-closing metathesis between a ruthenium carbene and the norbornene moiety.
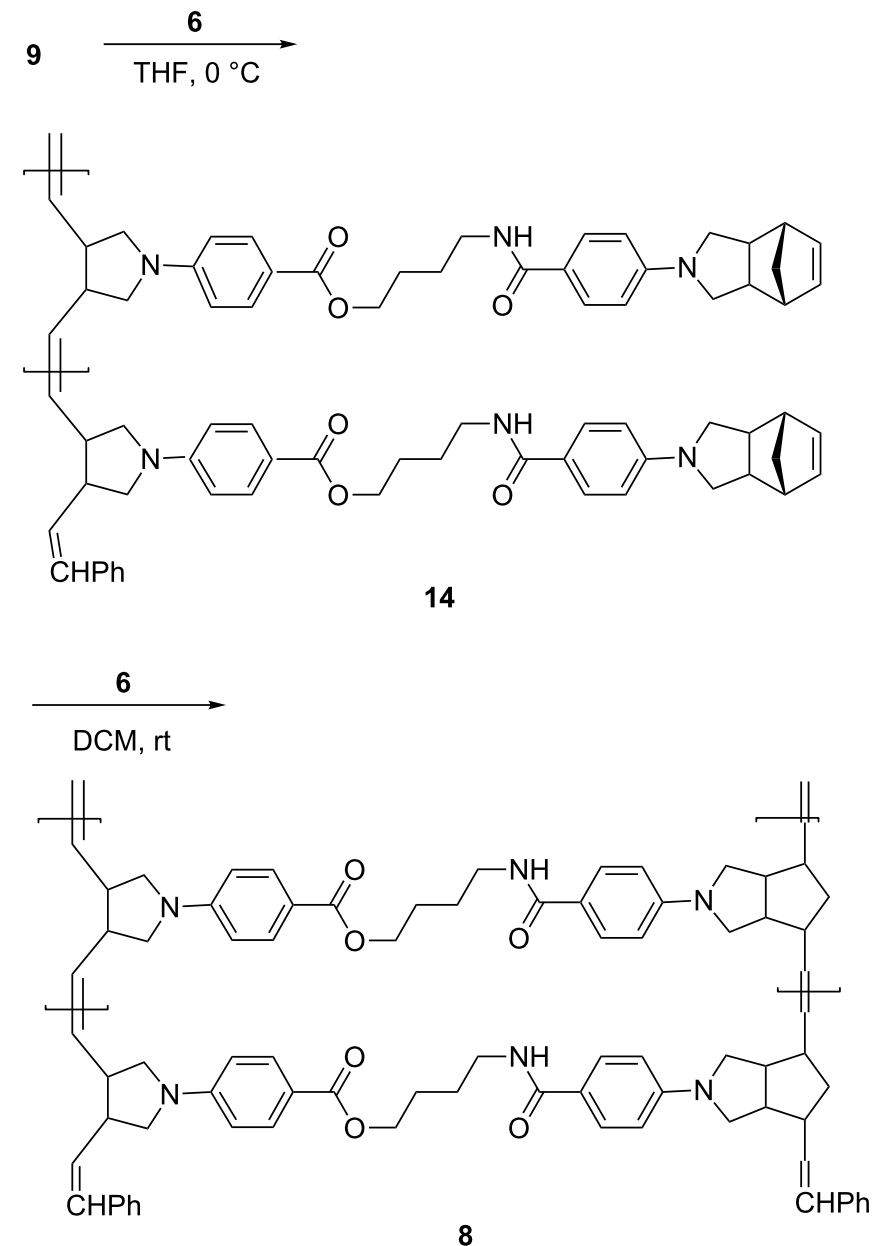


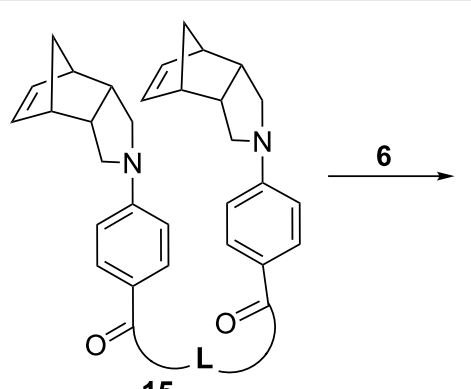

15
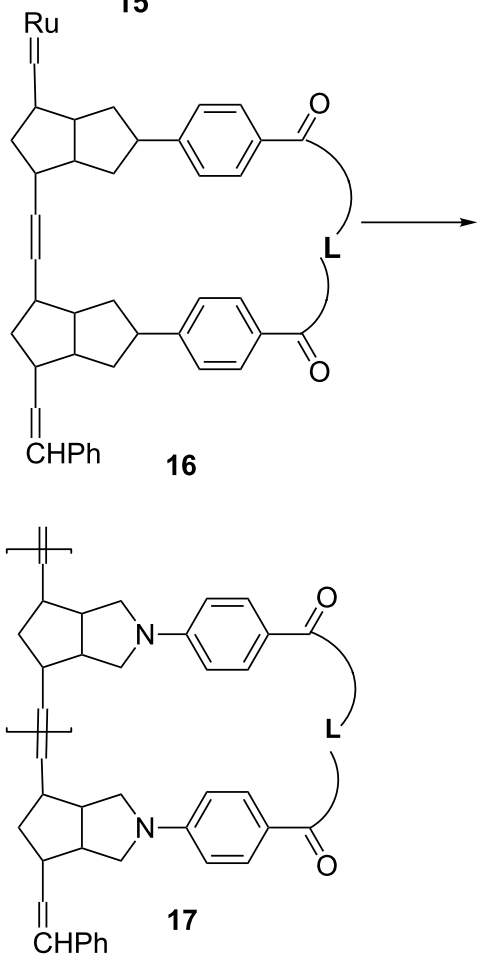

Scheme 6: Cyclopolymerization of 15 with a flexible linker.

Polymer 14 was treated with $10 \mathrm{~mol} \% \mathbf{6}$ in DCM at rt to give 8 in $95 \%$ yield. The ${ }^{1} \mathrm{H}$ NMR spectrum of $\mathbf{8}$ shows that the relative intensity of the signals around $\delta 5.4 \mathrm{ppm}$ was doubled, all signals due to olefinic protons in $\mathbf{9}$ and $\mathbf{1 4}$ being diminished.

\section{Methanolysis of unsymmetrical ladderphane}

In order to confirm the uniformity of the polymerization leading to the formation of unsymmetrical ladderphane $\mathbf{8}$, methanolysis of 8 with $\mathrm{NaOMe}$ in methanol at rt gave 7 and 18. Chloroform was then added and $\mathbf{1 8}$ was collected as a grayish precipitate in $56 \%$ yield. After filtration, the filtrate was worked up to afford 7 in $64 \%$ yield with a degree of polymerization of 10 $\left(M_{\mathrm{n}}=2500\right.$, PDI $\left.=1.11\right)$, in good agreement with those of $\mathbf{1 4}$ and 8 . The ${ }^{13} \mathrm{C}$ NMR spectrum of 7 shows two peaks at $\delta 40.6$ and $45.4 \mathrm{ppm}$, attributed to the allylic carbons attached to a $c i s$ and a trans double bond [13], respectively, and the relative ratio of these two peaks is roughly 7:3. This result suggests that about $70 \%$ of the double bonds in 7 might adopt cis configuration. Moreover, no norbornene moiety was detected by NMR on the polymeric backbones in 7 (Scheme 7).

Since 18 was insoluble in most organic solvents, acetylation of 18 with excess acetic anhydride and pyridine at $70{ }^{\circ} \mathrm{C}$ for $10 \mathrm{~h}$ gave the corresponding acetate 19 , which had good solubility in DCM or chloroform. GPC analysis showed that the degree of polymerization of $19(\mathrm{DP}=10, \mathrm{PDI}=1.24)$ was again comparable with that of the corresponding ladderphane $\mathbf{8}$, polycyclobutene 7 and 14.

The ${ }^{1} \mathrm{H}$ NMR spectrum of 19 shows peaks at $\delta 5.6$ and $5.3 \mathrm{ppm}$ attributed to trans and cis olefinic protons, respectively, in a ratio of 8 to 1 . It is well documented that 6 -catalyzed ROMP of $\mathrm{N}$-arylpyrrolidene appended norbornene gives polynorbornene with all double bonds in trans configuration [44-46]. The existence of both $Z$ - and $E$-double bonds in the parent polycyclobutene backbone in $\mathbf{1 4}$ may influence the stereoselectivity of the polynorbornene strand in 7 during the course of ROMP.

\section{Conclusion}

In summary, we have demonstrated useful ROMP conditions to selectively transform cyclobutene derivatives into the corre-
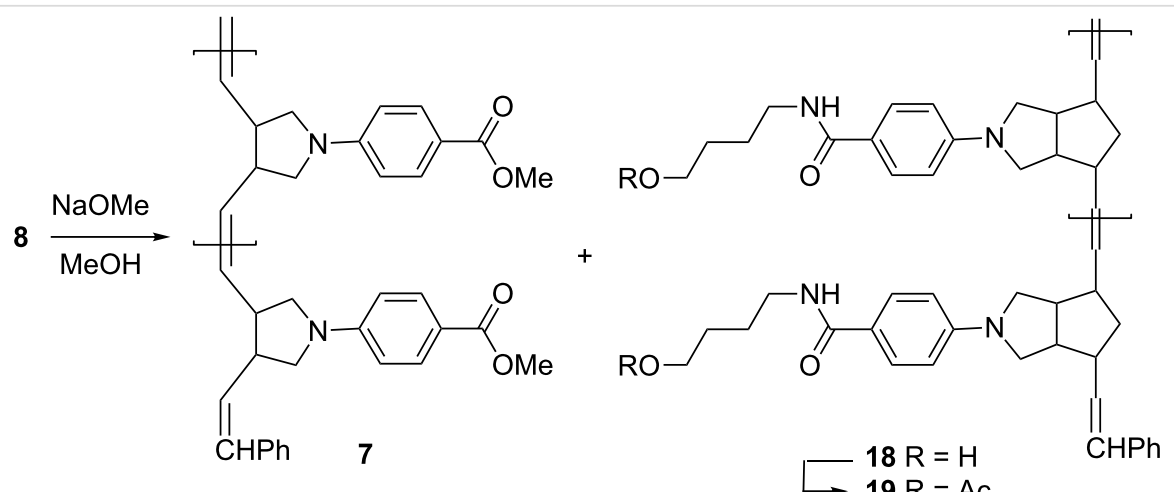

Scheme 7: Methanolysis of unsymmetrical ladderphane 8. 
sponding polycyclobutenes in $\mathrm{THF}$ at $0{ }^{\circ} \mathrm{C}$, whereas the corresponding norbornene skeleton appears to be unreactive under these conditions. This protocol has been used for the selective synthesis of unsymmetrical ladderphane having polycyclobutene in one strand and polynorbornene in the other. Further applications of this selectivity to other systems are in progress in our laboratory.

\section{Experimental General}

Unless otherwise specified, all commercially available starting materials were used without further purification. All air and moisture-sensitive reactions were carried out under an atmosphere of dry nitrogen in a glove box. All ${ }^{1} \mathrm{H}$ and ${ }^{13} \mathrm{C}$ NMR spectra were recorded on a Varian 400 Unity Plus NMR spectrometer using $\mathrm{CDCl}_{3}$ as solvent at ambient temperature. Chemical shifts were expressed in parts per million using residual solvent protons as internal standards $\left({ }^{1} \mathrm{H}\right.$ : chloroform: $\left.7.26 \mathrm{ppm}\right)$. Gel permeation chromatography (GPC) was performed on a Waters GPC instrument equipped with Waters 1515 HPLC pump using Waters 2487 absorbance detector. Polymer (approximately $0.5 \mathrm{mg})$ in THF $(0.1 \mathrm{~mL})$ was filtered through a 0.5 -micron filter and $20 \mu \mathrm{L}$ of the sample was injected into Shodex KF-G, Styragel HR2, Styragel HR3 and Styragel HR4 column $(7.8 \times 300 \mathrm{~mm})$ with oven temperature at $40{ }^{\circ} \mathrm{C}$ using standard polystyrene samples $\left(1.84 \times 10^{5}\right.$ to $996 \mathrm{Da}$ ) for calibration. THF was used as eluent (flow rate $1.0 \mathrm{~mL} / \mathrm{min}$ ).

Synthesis of 12. Under $\mathrm{N}_{2}$ atomosphere, to $\mathbf{1 0 a}(560 \mathrm{mg}$, $2.2 \mathrm{mmol})$ in DCM $(20 \mathrm{~mL})$ was added oxalyl chloride $(0.4 \mathrm{~mL}$, $4.3 \mathrm{mmol})$ at $0{ }^{\circ} \mathrm{C}$. The mixture was gradually warmed to $\mathrm{rt}$ and then stirred for $1 \mathrm{~h}$. The solvent was removed in vacuo to give the crude acyl chloride $\mathbf{1 0 b}$, to which was added DCM $(15 \mathrm{~mL})$, DMAP (60 mg, $0.5 \mathrm{mmol})$ and $\mathrm{Et}_{3} \mathrm{~N}(2.0 \mathrm{~mL}, 15 \mathrm{mmol})$. 4-Amino-1-butanol (11, $178 \mathrm{mg}, 2.0 \mathrm{mmol})$ was then added slowly at $0{ }^{\circ} \mathrm{C}$. After stirring for $8 \mathrm{~h}$ at $\mathrm{rt}$, the mixture was poured into $\mathrm{H}_{2} \mathrm{O}(50 \mathrm{~mL})$ and DCM $(50 \mathrm{~mL})$. The organic layer was separated, washed with brine $(100 \mathrm{~mL})$ and dried $\left(\mathrm{MgSO}_{4}\right)$. The solvent was removed in vacuo and the residue was chromatographed on silica gel (DCM/MeOH 20:1) to afford 12 (515 mg, 79\%). mp 207-209 ${ }^{\circ} \mathrm{C}$; IR (KBr): v 3455, 3306, 3056, 2940, 2867, 1606, 1554, 1514, 1473, 1379, 1309, 1199, 1130, $1047,969,826,768,733,683 \mathrm{~cm}^{-1} ;{ }^{1} \mathrm{H}$ NMR $(400 \mathrm{MHz})$ $\delta 1.52(\mathrm{~d}, J=8.4 \mathrm{~Hz}, 1 \mathrm{H}), 1.61-1.70(\mathrm{~m}, 6 \mathrm{H}), 2.92-2.99(\mathrm{~m}$, $4 \mathrm{H}), 2.98-2.99(\mathrm{~m}, 2 \mathrm{H}), 3.09(\mathrm{~m}, 2 \mathrm{H}), 3.25-3.30(\mathrm{~m}, 2 \mathrm{H})$, $3.47-3.48(\mathrm{~m}, 2 \mathrm{H}), 3.71(\mathrm{t}, J=5.6 \mathrm{~Hz}, 2 \mathrm{H}), 6.15-6.16(\mathrm{~m}, 3 \mathrm{H})$, $6.39(\mathrm{~d}, J=9.0 \mathrm{~Hz}, 2 \mathrm{H}), 7.61(\mathrm{~d}, J=9.0 \mathrm{~Hz}, 2 \mathrm{H}) ;{ }^{13} \mathrm{C} \mathrm{NMR}$ (100 MHz): $\delta$ 26.8, 30.1, 39.8, 45.6, 46.8, 50.6, 52.2, 62.3, 110.7, 120.1, 127.9, 135.3, 148.9, 167.1; HRMS (FAB, $m / z)$ : calcd for $\mathrm{C}_{20} \mathrm{H}_{26} \mathrm{~N}_{2} \mathrm{O}_{2}, 326.1994$; found, 326.1997 .
Synthesis of 9. Under $\mathrm{N}_{2}$ atomosphere, to 13a $(321 \mathrm{mg}$, $1.4 \mathrm{mmol})$ in DCM $(20 \mathrm{~mL})$ was added oxalyl chloride $(0.4 \mathrm{~mL}$, $4.3 \mathrm{mmol}$ ) at $0{ }^{\circ} \mathrm{C}$. The mixture was gradually warmed to $\mathrm{rt}$ and then stirred for $1 \mathrm{~h}$. The solvent was removed in vacuo to give the crude acyl chloride $\mathbf{1 3 b}$, to which was added DCM $(15 \mathrm{~mL})$, DMAP (60 mg, $0.5 \mathrm{mmol})$ and $\mathrm{Et}_{3} \mathrm{~N}(2.0 \mathrm{~mL}, 15 \mathrm{mmol})$. Compound $12(522 \mathrm{mg}, 1.6 \mathrm{mmol})$ was then added slowly at $0{ }^{\circ} \mathrm{C}$. After stirring for $8 \mathrm{~h}$ at $\mathrm{rt}$, the mixture was poured into $\mathrm{H}_{2} \mathrm{O}$ $(50 \mathrm{~mL})$ and DCM $(50 \mathrm{~mL})$. The organic layer was separated, washed with saturated brine $(100 \mathrm{~mL})$ and dried $\left(\mathrm{MgSO}_{4}\right)$. The solvent was removed in vacuo and the residue was chromatographed on silica gel (DCM/MeOH 20:1) to afford 9 (512 mg, 70\%). mp 238-240 ${ }^{\circ} \mathrm{C}$; IR (KBr): v 3333, 3051, 2949, 2843, 1699, 1606, 1547, 1511, 1473, 1376, 1274, 1216, 1180, 1106, 1050, 963, 828, 769, $740 \mathrm{~cm}^{-1} ;{ }^{1} \mathrm{H}$ NMR (400 MHz) $\delta 1.51(\mathrm{~d}, J=8.2 \mathrm{~Hz}, 1 \mathrm{H}), 1.61(\mathrm{~d}, J=8.2 \mathrm{~Hz}, 1 \mathrm{H}), 1.72-1.85$ $(\mathrm{m}, 4 \mathrm{H}), 2.92-2.98(\mathrm{~m}, 6 \mathrm{H}), 3.07-3.09(\mathrm{~m}, 2 \mathrm{H}), 3.25-3.29(\mathrm{~m}$, 2H), 3.49-3.56 (m, 4H), $3.65(\mathrm{~d}, J=10.0 \mathrm{~Hz}, 2 \mathrm{H}), 4.30(\mathrm{t}$, $J=6.4 \mathrm{~Hz}, 2 \mathrm{H}), 6.03(\mathrm{~m}, 1 \mathrm{H}), 6.13-6.15(\mathrm{~m}, 4 \mathrm{H}), 6.38(\mathrm{~d}$, $J=8.6 \mathrm{~Hz}, 2 \mathrm{H}), 6.62(\mathrm{~d}, J=8.4 \mathrm{~Hz}, 2 \mathrm{H}), 7.61(\mathrm{~d}, J=8.6 \mathrm{~Hz}$, $2 \mathrm{H}), 7.87(\mathrm{~d}, J=8.4 \mathrm{~Hz}, 2 \mathrm{H}) ;{ }^{13} \mathrm{C} \mathrm{NMR}(100 \mathrm{MHz}) \delta 26.4$, 26.6, 39.4, 45.3, 46.4, 46.5, 48.8, 50.4, 52.0, 63.7, 110.8, 111.8, $117.5,120.4$, 128.0, 130.9, 135.5, 139.1, 149.1, 152.9, 166.6, 167.1; HRMS (FAB, $m / z$ ): calcd for $\mathrm{C}_{33} \mathrm{H}_{37} \mathrm{~N}_{3} \mathrm{O}_{3}, 523.2835$; found, 523.2839 .

Synthesis of 14. Under $\mathrm{N}_{2}$ atomosphere, to a solution of 9 $(84.0 \mathrm{mg}, 0.16 \mathrm{mmol})$ in THF $(10 \mathrm{~mL})$ was added $6(12.8 \mathrm{mg}$, $0.016 \mathrm{mmol})$ in THF $(1 \mathrm{~mL})$ at $0{ }^{\circ} \mathrm{C}$. After stirring at $0{ }^{\circ} \mathrm{C}$ for $4 \mathrm{~h}$, ethyl vinyl ether $(1.0 \mathrm{~mL})$ was then added and stirring was continued at $0{ }^{\circ} \mathrm{C}$ for $2 \mathrm{~h}$. The mixture was concentrated and the residual solution was added to methanol. The precipitate was collected and redissolved in DCM. Reprecipitation by adding the DCM solution to methanol afforded $\mathbf{1 4}$ as a grayish powder (74.8 mg, 89\%). IR (KBr): v 3350, 3054, 2954, 2847, 1695, 1605, 1512, 1476, 1381, 1275, 1179, 1107, 967, 827, 768, 733, $698 \mathrm{~cm}^{-1} ;{ }^{1} \mathrm{H}$ NMR $(400 \mathrm{MHz}) \delta 1.51-1.72(\mathrm{~m}, 6 \mathrm{H}), 2.92-3.48$ $(\mathrm{m}, 16 \mathrm{H}), 4.26(\mathrm{br}, 2 \mathrm{H}), 5.49(\mathrm{~m}, 2 \mathrm{H}), 6.12(\mathrm{br}, 2 \mathrm{H}), 6.36(\mathrm{~m}$, $5 \mathrm{H}), 7.63(\mathrm{br}, 2 \mathrm{H}), 7.86(\mathrm{br}, 2 \mathrm{H})$; degree of polymerization (DP) analysis: $\delta 7.86 / \delta 5.07=10$, indicating a DP of $10 ;{ }^{13} \mathrm{C} \mathrm{NMR}$ (100 MHz) $\delta 26.6,39.6,40.9,45.5,46.6,50.5,52.1,52.9,64.0$, $110.5,110.9,117.0,120.5,128.2,129.8,131.3,135.6,149.2$, $150.2,166.8,167.4$.

Synthesis of 8. Under $\mathrm{N}_{2}$ atomosphere, to a solution of $\mathbf{1 4}$ $(62.8 \mathrm{mg}, 0.12 \mathrm{mmol})$ in DCM $(40 \mathrm{~mL})$ was added $6(9.6 \mathrm{mg}$, $0.012 \mathrm{mmol})$ in DCM $(5 \mathrm{~mL})$. After stirring at $\mathrm{rt}$ for $4 \mathrm{~h}$, ethyl vinyl ether $(0.5 \mathrm{~mL})$ was then added and stirring was continued for $30 \mathrm{~min}$. The mixture was concentrated and the residual solution was added to methanol. The precipitate was collected and redissolved in DCM. Reprecipitation by adding the DCM solu- 
tion to methanol afforded 8 as a grayish powder $(59.7 \mathrm{mg}$, $95 \%)$. IR (KBr): v 3373, 3054, 2929, 2849, 1694, 1605, 1512, 1478, 1381, 1274, 1179, 1106, 966, 827, 767, 733, $697 \mathrm{~cm}^{-1}$; ${ }^{1} \mathrm{H}$ NMR (400 MHz) $\delta 1.47$ (br, 1H), $1.82(\mathrm{~m}, 5 \mathrm{H}), 2.88-3.49$ (m, 16H), 4.27 (br, 2H), $5.47(\mathrm{~m}, 4 \mathrm{H}), 6.49$ (m, 5H), 7.67-7.89 $(\mathrm{m}, 4 \mathrm{H})$; DP analysis: $\delta 4.27 / \delta 5.05=11$, indicating a DP of 11 . ${ }^{13} \mathrm{C}$ NMR $(100 \mathrm{MHz}) \delta 26.6,40.0,46.1,49.7,53.2,63.7,110.6$, $111.8,116.9,121.8,126.0,128.5,131.3,136.5,138.7,150.1$, $166.7,167.5$.

Synthesis of 7 and 18. To a solution of $8(52 \mathrm{mg}, 0.1 \mathrm{mmol}$ [calculated based on the molecular weight of the monomeric unit]) in DCM (20 mL) was added $30 \% \mathrm{NaOMe}$ in methanol $(6 \mathrm{~mL})$. The mixture was stirred at $50{ }^{\circ} \mathrm{C}$ for $20 \mathrm{~h}$ and cooled to rt. The insoluble solid residue was collected and dried to give crude 18 as a grayish solid (18 mg, 56\%). After filtration, the filtrate was washed with water and dried $\left(\mathrm{MgSO}_{4}\right)$. The mixture was concentrated and the residual solution was added to methanol. The precipitate was collected and redissolved in DCM. Reprecipitation by adding the DCM solution to methanol afforded 7 as a grayish powder (21 mg, 64\%). IR (KBr): v 3066, 2951, 2862, 1702, 1605, 1524, 1478, 1434, 1383, 1281, 1180, 1108, 970, 828, 769, 698, $507 \mathrm{~cm}^{-1}$; ${ }^{1} \mathrm{H}$ NMR (400 MHz)

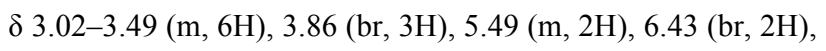
$7.87(\mathrm{br}, 2 \mathrm{H})$, DP analysis by integration of peaks at $\delta 6.43 / \delta 5.06=10$, indicating a DP of $10 .{ }^{13} \mathrm{C} \mathrm{NMR}(100 \mathrm{MHz})$ $\delta 40.8,45.8,51.6,52.7,110.5,117.1,128.4,129.7,131.3$, 150.2, 167.2. GPC: $M_{\mathrm{n}}=2500, M_{\mathrm{w}}=2800$, PDI $=1.11$.

Synthesis of 19. A mixture of crude 18 (16 mg, $0.05 \mathrm{mmol})$, obtained from the above experiment, in $\mathrm{Ac}_{2} \mathrm{O}(0.5 \mathrm{~mL})$ and pyridine $(5 \mathrm{~mL})$ was stirred at $70{ }^{\circ} \mathrm{C}$ for $10 \mathrm{~h}$. The solvent was concentrated and the residue was dissolved in $\mathrm{CHCl}_{3}(15 \mathrm{~mL})$ and washed first with diluted $\mathrm{HCl}(\mathrm{pH} 3)$ and then with water. The organic solvent was concentrated and the residual solution was added to methanol. The precipitate was collected and redissolved in $\mathrm{CHCl}_{3}$. Reprecipitation by adding the $\mathrm{CHCl}_{3}$ solution to methanol afforded 19 as a grayish powder (12 $\mathrm{mg}, 63 \%)$. ${ }^{1} \mathrm{H}$ NMR (400 MHz) $\delta 1.73$ (br, 6H) 2.05 (s, 3H), 2.73-3.62 (m, $10 \mathrm{H}), 4.07$ (br, 2H), 5.50 (m, 2H), 6.48 (br, 2H), 7.73 (br, 2H), DP $\delta 5.50 / \delta 5.05=10$, indicating a DP of $10 .{ }^{13} \mathrm{C} \mathrm{NMR}$ (100 MHz) $\delta 21.1,28.0,39.7,45.0,46.5,50.8,64.3,112.2$, $121.9,128.5,131.8,132.0,150.5,168.1,171.6$.

\section{General procedure for kinetic measurements}

Monomer 4 or $5(0.03 \mathrm{mmol})$ was dissolved in DCM- $d_{2}$ or THF- $d_{8}(0.5 \mathrm{~mL})$ and was syringed into an NMR tube inside a glove-box under nitrogen atmosphere. The NMR tube was then covered with a standard tube cap and placed in the NMR spectrometer. The tube was left to equilibrate at the desired temperature and all parameters were adjusted. A solution of 6 (24 mg in
$1.0 \mathrm{~mL}$ of the same solvent) was prepared under nitrogen atmosphere prior to the reaction. Catalyst $6(10 \mathrm{~mol} \%)$ was syringed into the NMR tube which was immediately put in the NMR probe again. The reaction was monitored by the decrease of the peak intensity for $\mathrm{H}-2$ using the peaks for $\mathrm{H}-1$ and $\mathrm{H}-1$ ' as the internal reference (Supporting Information File 1, Figures S8-S10). The spectra were recorded every ten to twenty minutes interval depending on the reaction (Figures S8-S10). The rate constants were thus obtained (Figures S1 and S2).

\section{Supporting Information}

\section{Supporting Information File 1}

${ }^{1} \mathrm{H}$ and ${ }^{13} \mathrm{C}$ NMR spectra of both monomers and polymers, as well as GPC and kinetic investigation results.

[https://www.beilstein-journals.org/bjoc/content/ supplementary/1860-5397-15-4-S1.pdf]

\section{Acknowledgement}

We thank the Ministry of Science and Technology in Taiwan for support of this work. YK thanks Shanghai Institute of Organic Chemistry for a fellowship.

\section{References}

1. Buchmeiser, M. R. Chapter 19. In Synthesis of Polymers; Schlüter, A. D.; Hawker, C. J.; Sakamoto, J., Eds.; Wiley-VCH, 2012.

2. Buchmeiser, M. R. Chem. Rev. 2000, 100, 1565-1604. doi:10.1021/cr990248a

3. Grubbs., R. H.; Khosravi, E., Eds. Handbook of Metathesis. Polymer Synthesis, 2nd ed.; Wiley-VCH, 2015; Vol. 3.

4. Luh, T.-Y. Acc. Chem. Res. 2013, 46, 378-389. doi:10.1021/ar300170b

5. Luh, T.-Y.; Ding, L. Tetrahedron 2017, 73, 6487-6513. doi:10.1016/j.tet.2017.09.029

6. Yang, H.-C.; Lin, S.-Y.; Yang, H.-C.; Lin, C.-L.; Tsai, L.; Huang, S.-L.; Chen, I. W.-P.; Chen, C.-h.; Jin, B.-Y.; Luh, T.-Y. Angew. Chem., Int. Ed. 2006, 45, 726-730. doi:10.1002/anie.200503406

7. Yang, H.-C.; Lee, S.-L.; Chen, C.-h.; Lin, N.-T.; Yang, H.-C.; Jin, B.-Y.; Luh, T.-Y. Chem. Commun. 2008, 6158-6160. doi:10.1039/b814672a

8. Chou, C.-M.; Lee, S.-L.; Chen, C.-H.; Biju, A. T.; Wang, H.-W.; Wu, Y.-L.; Zhang, G.-F.; Yang, K.-W.; Lim, T.-S.; Huang, M.-J.; Tsai, P.-Y.; Lin, K.-C.; Huang, S.-L.; Chen, C.-h.; Luh, T.-Y. J. Am. Chem. Soc. 2009, 131, 12579-12585. doi:10.1021/ja9035362

9. Yang, K.-W.; Xu, J.; Chen, C.-H.; Huang, H.-H.; Yu, T. J.-Y.; Lim, T.-S.; Chen, C.-h.; Luh, T.-Y. Macromolecules 2010, 43, 5188-5194. doi:10.1021/ma100550q

10. Chen, C.-W.; Chang, H.-Y.; Lee, S.-L.; Hsu, I.-J.; Lee, J.-J.; Chen, C.-h.; Luh, T.-Y. Macromolecules 2010, 43, 8741-8746. doi:10.1021/ma101956n

11. Wang, H.-W.; Chen, C.-H.; Lim, T.-S.; Huang, S.-L.; Luh, T.-Y. Chem. - Asian J. 2011, 6, 524-533. doi:10.1002/asia.201000492 
12. Huang, H.-H.; Chao, C.-G.; Lee, S.-L.; Wu, H.-J.; Chen, C.-h.; Luh, T.-Y. Org. Biomol. Chem. 2012, 10, 5948-5953. doi:10.1039/c2ob25114k

13. Yeh, N.-H.; Chen, C.-W.; Lee, S.-L.; Wu, H.-J.; Chen, C.-h.; Luh, T.-Y. Macromolecules 2012, 45, 2662-2667. doi:10.1021/ma300027k

14. Xu, J.; Zhang, Z.; Liu, Y.-H.; Guo, Q.; Wang, G.-W.; Lai, G.; Luh, T.-Y. J. Polym. Sci., Part A: Polym. Chem. 2017, 55, 2999-3010. doi:10.1002/pola.28572

15. Zhu, L.; Flook, M. M.; Lee, S.-L.; Chan, L.-W.; Huang, S.-L.; Chiu, C.-W.; Chen, C.-H.; Schrock, R. R.; Luh, T.-Y. Macromolecules 2012, 45, 8166-8171. doi:10.1021/ma301686f

16. Chen, C.-H.; Satyanarayana, K.; Liu, Y.-H.; Huang, S.-L.; Lim, T.-S.; Luh, T.-Y. Chem. - Eur. J. 2015, 21, 800-807. doi:10.1002/chem.201403806

17. Zhu, L.; Lin, N.-T.; Xie, Z.-Y.; Lee, S.-L.; Huang, S.-L.; Yang, J.-H.; Lee, Y.-D.; Chen, C.-h.; Chen, C.-H.; Luh, T.-Y. Macromolecules 2013 , 46, 656-663. doi:10.1021/ma302293q

18. Lin, N.-T.; Xie, C.-Y.; Huang, S.-L.; Chen, C.-H.; Luh, T.-Y. Chem. - Asian J. 2013, 8, 1436-1440. doi:10.1002/asia.201300222

19. Lin, N.-T.; Lin, S.-Y.; Lee, S.-L.; Chen, C.-h.; Hsu, C.-H.; Hwang, L. P.; Xie, Z.-Y.; Chen, C.-H.; Huang, S.-L.; Luh, T.-Y. Angew. Chem., Int. Ed. 2007, 46, 4481-4485. doi:10.1002/anie.200700472

20. Lai, G.; Luh, T.-Y. Bull. Chem. Soc. Jpn. 2018, 91, 262-273. doi:10.1246/bcsj.20170354

21. Ke, Y.-Z.; Lee, S.-L.; Chen, C.-h.; Luh, T.-Y. Chem. - Asian J. 2011, 6 , 1748-1751. doi:10.1002/asia.201000877

22. Ke, Y.-Z.; Ji, R.-J.; Wei, T.-C.; Lee, S.-L.; Huang, S.-L.; Huang, M.-J.; Chen, C.-h.; Luh, T.-Y. Macromolecules 2013, 46, 6712-6722. doi:10.1021/ma4012363

23. Moatsou, D.; Hansell, C. F.; O'Reilly, R. K. Chem. Sci. 2014, 5 , 2246-2250. doi:10.1039/c4sc00752b

24. Lutz, J.-F., Ed. Sequence-Controlled Polymers; Wiley-VCH Verlag GmbH: Weinheim, Germany, 2018. doi:10.1002/9783527806096

25. Wu, Z.; Wheeler, D. R.; Grubbs, R. H. J. Am. Chem. Soc. 1992, 114 146-151. doi:10.1021/ja00027a021

26. Wu, Z.; Grubbs, R. H. Macromolecules 1994, 27, 6700-6703. doi:10.1021/ma00101a002

27. Perrott, M. G.; Novak, B. M. Macromolecules 1995, 28, 3492-3494. doi:10.1021/ma00113a062

28. Perrott, M. G.; Novak, B. M. Macromolecules 1996, 29, 1817-1823 doi:10.1021/ma951516j

29. Maughon, B. R.; Grubbs, R. H. Macromolecules 1997, 30, 3459-3469. doi:10.1021/ma961780s

30. Charvet, R.; Novak, B. M. Macromolecules 2001, 34, 7680-7685. doi:10.1021/ma0109875

31. Lee, J. C.; Parker, K. A.; Sampson, N. S. J. Am. Chem. Soc. 2006, 128, 4578-4579. doi:10.1021/ja058801v

32. Song, A.; Parker, K. A.; Sampson, N. S. J. Am. Chem. Soc. 2009, 131 3444-3445. doi:10.1021/ja809661k

33. Parker, K. A.; Sampson, N. S. Acc. Chem. Res. 2016, 49, 408-417. doi:10.1021/acs.accounts.5b00490

34. Lin, N.-T.; Ke, Y.-Z.; Satyanarayana, K.; Huang, S.-L.; Lan, Y.-K.; Yang, H.-C.; Luh, T.-Y. Macromolecules 2013, 46, 7173-7179. doi:10.1021/ma401007b

35. Greenberg, A.; Liebman, J. F. Strained organic molecules; Academic Press: New York, 1978.

36. Schwab, P.; Grubbs, R. H.; Ziller, J. W. J. Am. Chem. Soc. 1996, 118, 100-110. doi:10.1021/ja952676d
37. Rule, J. D.; Moore, J. S. Macromolecules 2002, 35, 7878-7882. doi:10.1021/ma0209489

38. Wenzel, A. G.; Grubbs, R. H. J. Am. Chem. Soc. 2006, 128, 16048-16049. doi:10.1021/ja0666598

39. Beligny, S.; Blechert, S. In N-Heterocyclic Carbenes in Synthesis; Nolan, S. P., Ed.; Wiley-VCH: Weinheim, 2006.

40. van der Eide, E. F.; Piers, W. E. Nat. Chem. 2010, 2, 571-576. doi:10.1038/nchem.653

41. Cazalis, C.; Héroguez, V.; Fontanille, M. Macromol. Chem. Phys. 2000, 201, 869-876. doi:10.1002/(sici)1521-3935(20000501)201:8<869::aid-macp869>3.3.c o;2-q

42. Al Samak, B.; Amir-Ebrahimi, V.; Corry, D. G.; Hamilton, J. G.; Rigby, S.; Rooney, J. J.; Thompson, J. M. J. Mol. Catal. A: Chem. 2000, 160, 13-21. doi:10.1016/s1381-1169(00)00228-4

43. Matos, J. M. E.; Lima-Neto, B. S. J. Mol. Catal. A: Chem. 2005, 240, 233-238. doi:10.1016/j.molcata.2005.07.003

44. Sattigeri, J. A.; Shiau, C.-W.; Hsu, C. C.; Yeh, F.-F.; Liou, S.; Jin, B.-Y.; Luh, T.-Y. J. Am. Chem. Soc. 1999, 121, 1607-1608. doi:10.1021/ja983433z

45. Lin, W.-Y.; Murugesh, M. G.; Sudhakar, S.; Yang, H.-C.; Tai, H.-C.; Chang, C.-S.; Liu, Y.-H.; Wang, Y.; Chen, I.-W. P.; Chen, C.-h.; Luh, T.-Y. Chem. - Eur. J. 2006, 12, 324-330. doi:10.1002/chem.200500770

46. Lin, W.-Y.; Wang, H.-W.; Liu, Z.-C.; Xu, J.; Chen, C.-W.; Yang, Y.-C.; Huang, S.-L.; Yang, H.-C.; Luh, T.-Y. Chem. - Asian J. 2007, 2, 764-774. doi:10.1002/asia.200700011

\section{License and Terms}

This is an Open Access article under the terms of the Creative Commons Attribution License (http://creativecommons.org/licenses/by/4.0). Please note that the reuse, redistribution and reproduction in particular requires that the authors and source are credited.

The license is subject to the Beilstein Journal of Organic Chemistry terms and conditions: (https://www.beilstein-journals.org/bjoc)

The definitive version of this article is the electronic one which can be found at: doi:10.3762/bjoc. 15.4 